\title{
Perancangan Sistem Informasi Akuntansi Pengontrol Arus Kas (SIAPAK)
}

\author{
Ratnawati $^{1}$, Patimah Ulwiyah ${ }^{2}$ Dea Julianti Siswoyo ${ }^{3}$ \\ 1,2,3 Universitas Bina Sarana Informatika Kampus Kabupaten Karawang, Jalan Banten No.1 Karangpawitan, \\ Karawang, Jawa Barat, Indonesia \\ Email: ratnawati.rtx@bsi.ac.id
}

\begin{abstract}
Financial reports is an important role for top management to make decisions for the smooth running of the company going forward. One of the important elements of the financial statements is the cash flow statement which describes the company's financial condition in real terms. The Delta Tutoring Institute from the beginning of its operation until now still uses the method of inputting data of incoming funds and funds issued conventionally where this often causes problems such as cash flow reports which is inconsistent with the actual situation. This is due to incomplete transaction evidence so that there is often a difference between the amount of recorded funds and the funds at the end of the recording period. In addition, cash data collection with this method often experiences problems when the reporting period arrives, employees must recap the cash data to be used as cash reports to the leadership. Development of an accounting information system can be a solution to these problems. The use of the RAD (Rapid Application Development) method was chosen because of the advantages of this method, which is that it can assist in the creation of an information system ith a time that tends to be short. The purpose for this company is to control company funds, both revenue and use of company funds efficiently. The result is that it can improve the performance and speed of employees in recording cash transactions so that they are considered more effective.
\end{abstract}

Keywords: Rapid Application Development, cash flow, Accounting Information System

\begin{abstract}
ABSTRAK
Laporan keuangan berperan penting bagi top management untuk mengambil keputusan dalam pengembangan perusahaan. Salah satu unsur penting yang dimaksud yakni laporan tentang aliran dana kas yang masuk dan keluar yang menggambarkan kondisi keuangan perusahaan secara real. Lembaga Bimbingan Belajar Delta dari awal beroperasi hingga sekarang masih menggunakan metode input data dana yang masuk dan dana yang dikeluarkan secara konvensional dimana hal tersebut sering menyebabkan permasalahan seperti laporan arus kas yang tidak sesuai dengan realitas yang terjadi. Hal ini dikarenakan bukti transaksi yang tidak lengkap sehingga sering terjadi selisih pada jumlah dana yang tercatat dan dana yang ada di akhir periode pencatatan. Selain itu, pendataan kas dengan metode ini sering mengalami kendala di akhir periode pelaporan, karyawan harus melakukan rekap ulang data kas tersebut untuk dijadikan laporan kas kepada pimpinan. Pembangunan sistem informasi akuntansi dapat menjadi solusi bagi permasalahan tersebut. Penggunaan metode RAD (Rapid Application Development) dipilih karena keunggulan metode ini yakni dapat membantu dalam pembangunan sebuah sistem informasi dalam waktu yang relatif singkat. Tujuan pembangunan aplikasi ini adalah agar perusahaan ini dapat melakukan pengontrolan dana perusahaan baik pendapatan maupun penggunaan dana perusahaan secara efisien. Hasil dari pembangunan aplikasi ini yakni dapat meningkatkan kinerja serta kecepatan karyawan dalam melakukan pencatatan transaksi kas sehingga dinilai lebih efektif.
\end{abstract}

Kata Kunci: Rapid Application Development, arus kas, Sistem Informasi Akuntansi

\section{Pendahuluan}

Pengontrolan kas yang ada di suatu lembaga atau perusahaan merupakan unsur yang penting untuk mendapat perhatian khusus. Lembaga bimbingan belajar Delta sudah menggunakan komputer dalam pencatatan data pendapatan dan pengeluarannya, namun penggunaan komputer ini masih sangat terbatas yakni dengan spreedsheet sederhana dimana karyawan memindahkan pencatatan pendapatan dan pengeluaran secara manual dan satu per satu. Pihak lembaga juga telah mengakui bahwa hal ini sering menyebabkan permasalahan karena karyawan tersebut harus merekap data yang bersumber dari nota-nota serta kwitansi pada suatu waktu tertentu. Pada era 
Revolusi Industri 4.0 juga percepatan teknologi yang semakin massif, peran teknologi informasi dalam berbagai bidang dalam suatu unit juga berkembang pesat. Teknologi semakin maju dan kemajuan tersebut harus dimanfaatkan sebaik mungkin. Tantangan yang dihadapi dalam revolusi industri 4.0 antara lain: 1) Masalah keamanan teknologi informasi, 2) Keandalan dan stabilitas mesin produksi, 3) Kurangnya keterampilan yang memadai, 4) Keengganan untuk berubah oleh pemangku kepentingan, 5) Kehilangan banyak pekerjaan karena perubahan menjadi otomatisasi [1].

Permasalahan lain timbul pada saat pembuatan laporan pendapatan secara periodik yang harus dibuat. Dengan pencatatan yang ada, karyawan harus membuat serta menghitung kembali dana kas yang ada sehingga laporan dibuat relatif lebih lama. Hal ini diperkuat oleh pernyataan [2] yang menyatakan bahwa pengolahan data secara manual membutuhkan durasi waktu dan tenaga yang relatif lama serta akurasi laporan keuangan dapat diragukan. Dengan adanya permasalahan di atas, maka penting untuk melakukan pengembangan serta penerapan sebuah aplikasi yang dapat dijadikan porblem solving bagi perusahaan sehingga permasalahan tersebut dapat teratasi.

Beberapa penelitian terdahulu membuktikan bahwa dengan penerapan sistem informasi akuntansi arus kas dapat memberikan kemudahan dan meningkatkan kinerja lebih efektif dan efisien. Hasil penelitian [3] mengatakan bahwa membangun web arus kas dapat membuat laporan cash flow dengan mudah dan lebih efisien. Penelitian lain [4] menyebutkan bahwa sistem arus kas yang dibuat dapat memberikan pegawai kantor desa Bobaneigo kemudahan pada saat membuat laporan. Selain itu penerapan SI (Sistem Informasi) arus kas dapat dinilai efektif dengan skor nilai 82,00 yang terlihat dengan tidak terjadinya error pada interaksi sistem dan pengguna [5]. Sedangkan penelitian [6] menjelaskan bahwa SI kas masuk dan kas keluar yang dirancang akan membantu kinerja dari PT. Rakha Rekananta dari segi olahan data yang memiliki kaitan dengan kas. Kemudian menurut Merystika Kabuhung dalam penelitiannya menjelaskan bahwa sistem informasi akuntansi penerimaan dan pengeluaran kas dalam rangka perencanaan dan pengendalian keuangan berjalan efektif, karena telah sesuai dan memenuhi unsur-unsur pokok suatu sistem informasi akuntansi dan prosedur-prosedur pengendalian internal [7]. Dari beberapa penelitian terdahulu hampir semua menggunakan metode klasik waterfall, sedangkan sistem usulan yang dirancang oleh penulis akan menggunakan metode RAD (Rapid Application Development). Selain itu keunggulan yang diberikan pada pembangunan sistem informasi akuntansi ini adalah adanya penerapan penjurnalan secara langsung dengan memilih akun-akun yang dibutuhkan dalam setiap pencatatan transaksinya.

Tujuan pembuatan sistem informasi yang penulis beri nama SIAPAK ini adalah sebagai sebuah solusi untuk meningkatkan performa kinerja karyawan agar dapat bekerja lebih cepat, rapi dan efisien. Selain itu juga dapat mengurangi adanya kesalahan dalam penyusunan laporan dana kas perusahaan. Sistem Informasi Akuntansi digunakan untuk mengumpulkan, memproses, dan melaporkan informasi yang berkaitan dengan aspek keuangan dari peristiwa bisnis. Sistem Informasi Akuntansi mencatat dan melaporkan transaksi bisnis dan aliran dana dalam organisasi dan kemudian menghasilkan Laporan Keuangan[8].

\section{Metode}

Pada proses pengembangan sebuah sistem informasi, metode yang digunakan sangat banyak. Salah satu dari metode itu adalah pengembangan dengan model Rapid Application Development atau biasa disingkat RAD. Pemilihan metode ini dikarenakan metode ini memiliki keunggulan dalam hal durasi pengembangan sistem yang lebih efisien jika dibandingkan dengan metode lainnya[9]. RAD sendiri dapat diartikan sebagai sebuah metode waterfall yang diadaptasi dengan meningkatkan kecepatan pengembangannya, sehingga waktu pengerjaanya relatif singkat[10].

Tahapan penerapan metode RAD pada pengembangan produk software ini terdiri dari 3 tahapan utama [11] yaiitu: 
1. Merencanakan syarat-syarat pengembangan

Tahapan ini dapat dilakukan dengan menghimpun data-data, baik data utama(primer) atau data pendukung (sekunder). Dari proses menghimpun data tersesebut maka dapat dilakukan identifikasi terhadap tujuan pembangunan sistem serta mencari solusi dari masalah yang ditemukan.

2. Workhsop rancangan sistem

Terdapat dua proses pada tahapan ini yakni bekerjasama dengan pengguna sistem mengenai rancangan sistem dan proses pembangunan sistem itu sendiri. Dalam tahap ini terlihat jelas bahwa pengembang sistem harus melakukan komunikasi dengan pengguna sistem agar tercapainya rancangan sistem yang sesuai dengan kebutuhan penggunanya. Pada tahapan inilah akan terjadi iterasi dari rancangan sistem sampai mencapai kesepakatan.

3. Penerapan atau implementasi

Setelah rancangan yang dibutuhkan terpenuhi, tentu tahapan akhir adalah penerapan sistem dan melakukan uji coba terhadap sistem yang dibangun.

Dari tiga tahapan di atas, metode Rapid Application Development (RAD) dapat digambarkan sebagai berikut:

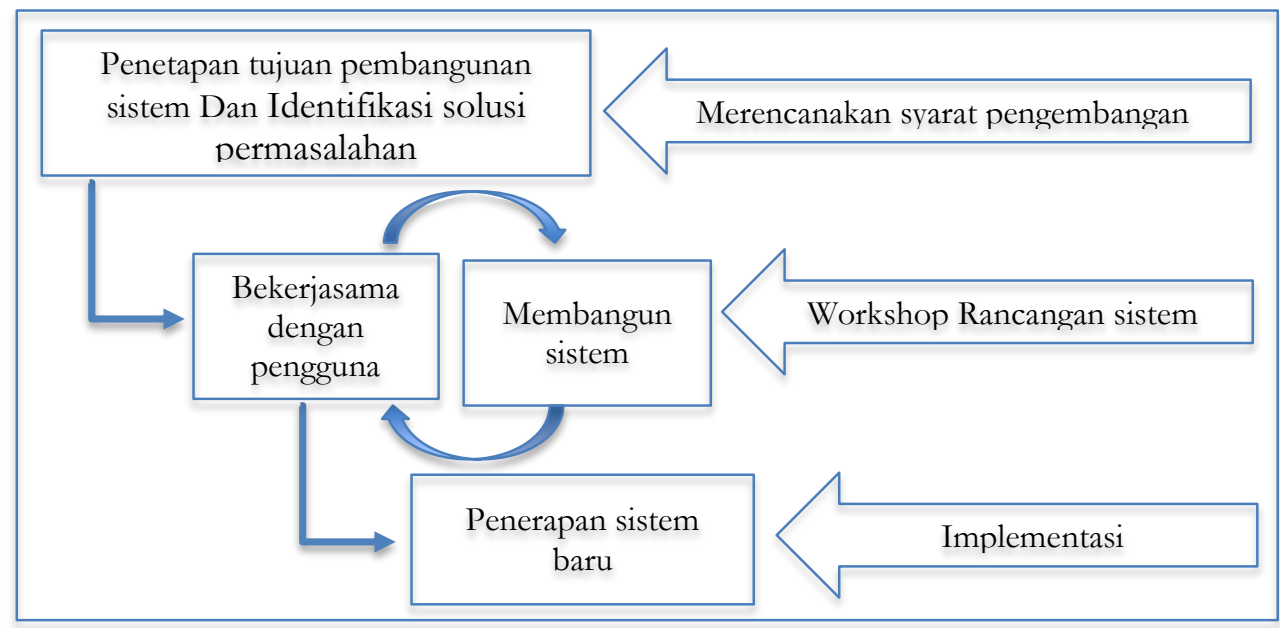

Gambar 1. Tahapan Metode RAD

\section{Hasil dan Pembahasan}

Lembaga Bimbingan Belajar Delta atau biasa disingkat LBB Delta merupakan sebuah lembaga belajar yang memberikan jasa bimbingan belajar mulai dari sekolah menengah pertama sampai jenjang menengah atas. LBB Delta ini telah memiliki cabang yang cukup banyak di beberapa kota di Indonesia. Lembaga pertama didirikan di daerah Jember Jawa Timur pada tahun 2004. Pada tahun 2018 LBB Delta juga membuka cabang di kota Karawang.

Arus kas adalah sebuah aliran dana kas yang masuk dan aliran dana kas yang keluar atau yang setara dengan kas[12]. Agar pembahasan tidak terlalu luas, maka Sistem Informasi Akuntansi Pengontrol Arus Kas (SIAPAK) yang dibangun ini memiliki ruang lingkup yang hanya diterapkan pada LBB Delta cabang kota Karawang saja. Seperti penjelasan dan pemaparan di atas, dimana SIAPAK ini dibangun dengan metode RAD yang memiliki tiga tahapan utama. Setiap tahapan dilakukan dengan berbagai kegiatan sehingga produk sistem informasi yang dibuat akan sampai pada tujuan yang telah diingikan. Berikut ini tahapan penerapan metode yang penulis pilih.

A. Tahap Merencanakan Syarat-Syarat Pengembangan (Require Planning)

Pada tahapan ini dilakukan pengumpulan data, analisa permasalahan serta pemaparan kebutuhan seorang pengguna sistem terhadap sistem yang akan dibangun. 
1. Pengumpulan Data

Kegiatan mencari dan mengumpulkan data utama/primer dilakukan dengan cara mewawancarai langsung kepada kepala unit LBB Delta cabang kota Karawang. Serta melakukan observasi mengenai proses pencatatan pada dana kas yang diterima dan juga yang dikeluarkan oleh LBB Delta cabang Karawang ini. Sedangkan untuk data sekunder dilakukan dengan metode kepustakaan dengan membaca referensi dari sumber-sumber kepustakaan yang mendukung tema masalah yang sedang diamati.

2. Analisis Data

Analsis data dilakukan dengan tujuan untuk mengetahui permasalahan serta mencari penyelesaian yang tepat dari persoalan yang ada. Dari analisa yang dilakuakan ini dapat dipaparkan mengenai proses penerimaan serta proses pengeluaran dana kas yang dilakukan oleh LBB Delta cabang Karawang sebagai berikut:

a) Prosedur Penerimaan Dana Kas

Penerimaan Kas pada LBB DELTA cabang Karawang berasal dari pendaftaran siswa baru dan pembayaran bimbingan belajar. Calon siswa baru yang ingin mendaftar bisa langsung mendatangi bagian admin. Admin akan menjelaskan program yang ada di LBB Delta kepada calon siswa dan menjelaskan rincian biaya bimbel berbentuk kertas yang berisi biaya pendaftaran, biaya bimbel serta jadwal kelas yang akan diambil oleh calon siswa. Jika calon siswa sudah yakin ingin mendaftar, admin akan memberikan form untuk pendaftaran untuk calon siswa agar diisi. Kemudian calon siswa baru membayar biaya pendaftaran dan biaya bimbingan, untuk biaya bimbingan bisa diangsur atau lunas. Setelah membayar, Admin akan membuatkan kwitansi dan memberikannya kepada siswa. Kemudian Admin akan menginput semua transaksi penerimaan kas ke data penerimaan dan pengeluaran di Microsoft excel. Sedangkan untuk dana dari pembayaran bimbingan belajar, peserta dapat melakukan pembayaran di awal sekaligus atau membayar setiap awal bulan.

b) Prosedur Pengeluaran Dana Kas

Transaksi pengeluaran Dana Kas bersumber pada pembayaran biaya-biaya operasional seperti membeli token listrik, pembelian peralatan kantor serta penggajian karyawan. Untuk pembayaran biaya-biaya operasional dilakukan oleh admin atas persetujuan Kepala Unit. Setelah mendapat persejutuan Kepala Unit, admin akan membeli keperluan yang telah habis dan menyimpan nota pembeliannya, kemudian diinput oleh Admin ke data penerimaan dan pengeluaran kas di Microsoft Excel. Sedangkan untuk penggajian dilakukan dengan cara admin menyerahkan absensi karyawan kepada kepala unit, kemudian kepala unit mengecek absen tersebut untuk menghitung gaji karyawan serta membuat 2 rangkap slip gaji, satu slip gaji untuk di tanda tangani dan diserahkan kepada karyawan dan satu slip gaji diberikan kepada admin untuk disimpan dan dicatat sebagai bukti pengeluaran kas.

c) Prosedur Pelaporan

Setiap akhir bulan, admin akan melakukan pengecekan terhadap bukti-bukti transaksi apakah sudah semua data di Microsoft Excel sesuai dengan bukti yang ada, apabila ada bukti transaksi yang belum diinput, maka admin akan melakukan koreksi kembali. Setelah semua data sesuai, admin menyerahkan data tersebut ke kepala unit dan kepala unit melakukan pengecekan ulang. Setelah itu kepala unit akan membuat laporan summary dari data tersebut dengan Microsoft Excel dan mengirimkannya ke kantor pusat melalui email.

Dari pemaparan di atas, beberapa permasalahan muncul seperti pencatatan bukti kas tertutama kas keluar terkadang tidak dicatat secara real time, artinya pencatatan data tersebut dapat dilakukan kapan saja sebelum memberikan data kepada kepala unit. Selain itu kepala unit akan 
membuat ulang laporan dari pencatatan transaksi dari admin secara manual dan mengirimkan hasilnya ke kantor pusat.

3. Analisa Kebutuhan Akan Sistem

Dari hasil temuan permasalahan di atas, perlu adanya sebuah sistem yang dapat menjadi solusi bagi lembaga tersebut. Namun sebelum sistem itu dibangun maka perlu adanya analisa berbagai kebutuhan fungsionalitas dari pengguna terhadap sistem yang akan dibangun. Berikut hasil analisa kebutuhan yang dilakukan.

Tabel 1. Kebutuhan Fungsional Sistem

\begin{tabular}{|l|l|}
\hline \multicolumn{1}{|c|}{ Admin } & \multicolumn{1}{c|}{ Kepala Unit } \\
\hline Login & Login \\
\hline Membuat akun-akun terkait dana kas & Melihat data pengguna sistem \\
\hline Mencatat transaksi dana kas masuk & Melihat dan mencetak laporan data kas masuk \\
\hline Mencatat transaksi dana kas keluar & Melihat dan mencetak laporan data kas keluar \\
\hline Logout & Logout \\
\hline
\end{tabular}

B. Tahap Worksop Rancangan Sistem (Design Workshop)

Pada tahapan ini terdiri dari beberapa kegiatan seperti perancangan kebutuhan fungsionalitas sistem dengan diagram use case, rancangan basis data dengan diagram relasi antar entitas, Uraian file dari basis data, penggambaran aliran sistem saat pengguna memakai sistem menggunakan diagram activty, serta desain antar muka pengguna dari SIAPAK itu sendiri.

1. Diagram Use Case

Diagram ini merupakan salah satu diagram yang menggambarkan perilaku bagaimana aktor melakukan interaksi terhadap sistem yang dibangun [13].

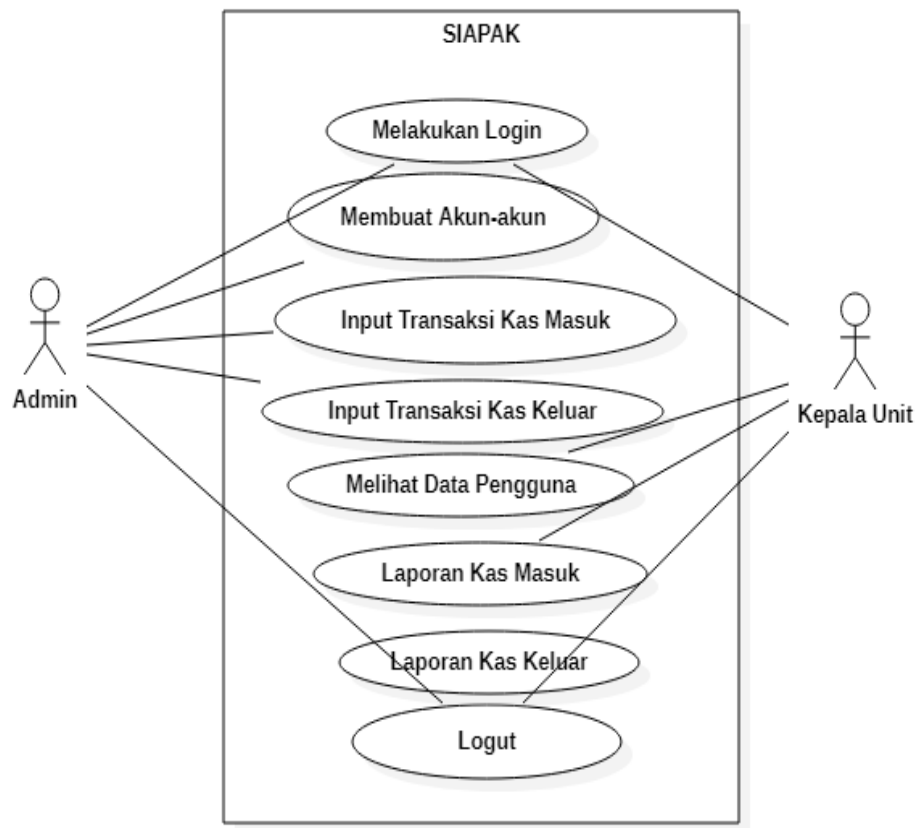

Gambar 2. Diagram Use Case SIAPAK

Pada gambar 2 di atas, menggambarkan fungsi-fungsi sistem apa saja yang dapat digunakan oleh penggunanya. Dalam kasus ini, pengguna terdiri dari dua pihak yakni admin sebagai 
pencatat transaksi sedangkan kepala unit yang dapat melihat serta mencetak laporan dana kas yang masuk dan keluar.

2. Rancangan Basis Data

Pada rancangan basis data, peneliti menggambarkannya pada sebuah diagram relasi antar entitas. Sebuah diagram relasi antar entitas atau yang lazim dinamai ERD (Entity Relationship Diagram) yakni gambaran model yang dapat menggambarkan serta menjelaskan relasi dari data-data yang tedapat pada sebuah database yang dalam penggunaanya menggunakan simbol atau notasi-notasi tertentu [14].

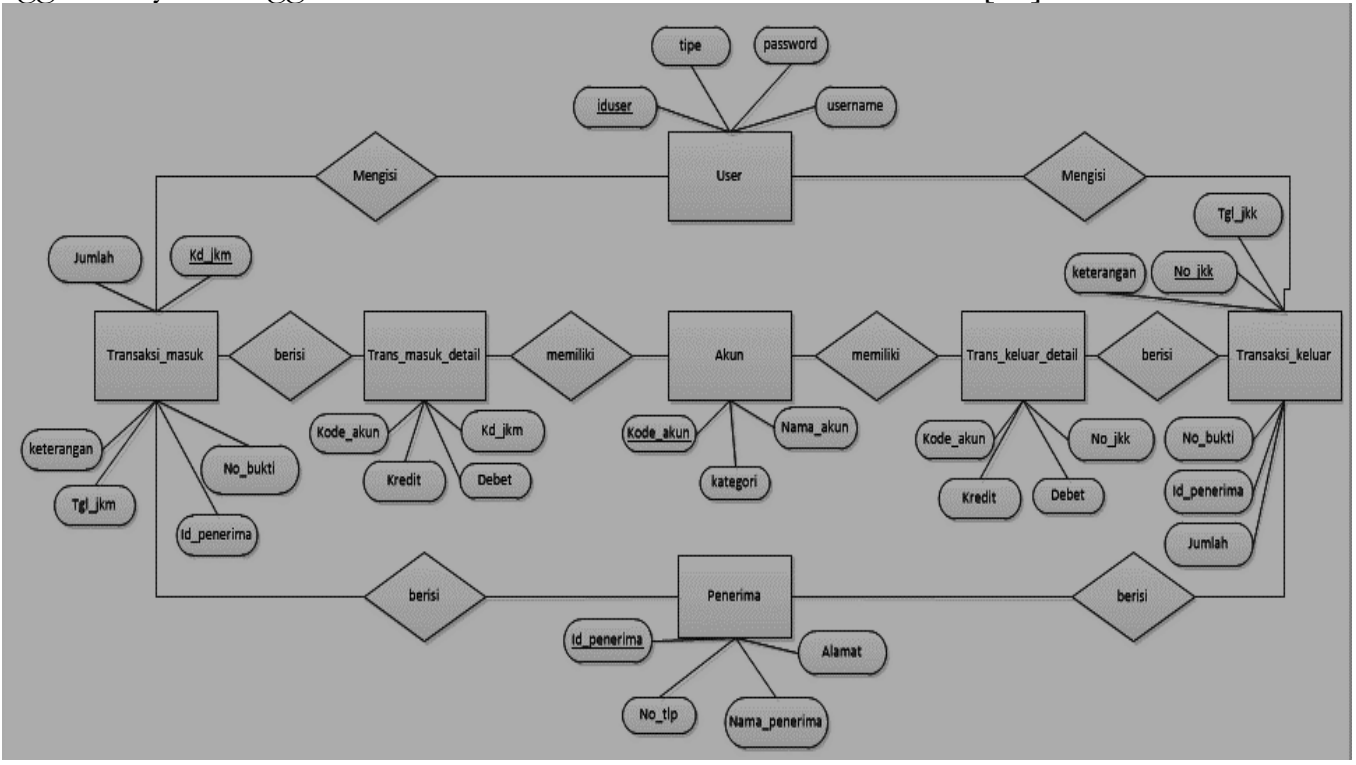

Gambar 3. Diagram Relasi Anatar Entitas SIAPAK

Dari gambar 3 dapat dilihat bahwa di dalam basis data yang dibuat terdiri dari 7 tabel yakni tabel user yang berisi pengguna sistem, tabel transaksi_masuk untuk menyimpan transaksi kas yang masuk, tabel trans_masuk_detail untuk menjelaskan akun apa saja yang terlibat, tabel akun untuk data akun-akun yang digunakan dalam pencatatan transaksi, tabel transaksi_keluar digunakan untuk data transaksi kas yang keluar, tabel trans_keluar_detail untuk menjelaskan akun yang digunakan saat transaksi kas yang keluar, serta tabel penerima yang digunakan untuk mencatat dari siapa dan ke pihak mana dana kas tersebut terdistribusikan.

3. Uraian File

a. Uraian File User

Tabel 2. Uraian File User

\begin{tabular}{|l|l|l|l|}
\hline Attribute & Data type & Length & Key \\
\hline Iduser & Char & 5 & Kunci Utama \\
\hline Tipe & Varchar & 20 & \\
\hline Username & Varchar & 8 & \\
\hline Password & Varchar & 10 & \\
\hline
\end{tabular}

Pada tabel 2 berisi mengenai sepsifikasi file user dimana file user ini digunakan untuk menampung data pengguna SIAPAK yang bisa diakses oleh kepala unit. 
b. Uraian File Penerima atau Sumber

Tabel 3. Uraian File Penerima

\begin{tabular}{|l|l|l|l|}
\hline Attribute & Data type & Length & Key \\
\hline Id_penerima & Char & 5 & Kunci Utama \\
\hline Nama_penerima & Varchar & 25 & \\
\hline Alamat & Varchar & 50 & \\
\hline notelp & Varchar & 8 & \\
\hline
\end{tabular}

File penerima yang digambarkan pada tabel 3 merupakan file yang berisi data orang atau pihak mana saja yang nantinya akan menjadi penerima dana atau pemberi dana kas. Seperti siswa bimbingan, lembaga PLN, toko tempat membeli peralatan kantor, karyawan dan lain sebagainya.

c. Uraian File Akun Perkiraan

Tabel 4. Uraian File Akun

\begin{tabular}{|l|l|l|l|}
\hline Attribute & Data type & Length & Key \\
\hline Kode_akun & Varchar & 6 & Kunci Utama \\
\hline Nama_akun & Varchar & 25 & \\
\hline Kategori & Varchar & 15 & \\
\hline
\end{tabular}

Tabel 4 merupakan uraian dari file master ke tiga yakni file akun. File ini digunakan untuk menampung akun-akun perkiraan yang digunakan saat pencatatan transaksi.

d. Uraian File Transaksi Kas Yang Masuk

Tabel 5. Uraian File Transaksi Masuk

\begin{tabular}{|l|l|l|l|}
\hline Attribute & Data type & Length & Key \\
\hline Kd_jkm & Varchar & 8 & Kunci Utama \\
\hline No_bukti & Varchar & 10 & \\
\hline Tgl_jkm & Date & Short date & \\
\hline Keterangan & Varchar & 50 & \\
\hline Jumlah & Double & & \\
\hline Id_penerima & Char & 5 & Kunci Tamu \\
\hline
\end{tabular}

Tabel 5 menguraikan file transaksi masuk yakni file yang digunakan untuk menyimpan data kas yang masuk seperti pencatatan pembayaran peserta bimbingan, pendaftaran baru perserta bimbingan atau pemasukan kas lainnya.

e. Uraian File Detail Kas Masuk

Tabel 6. Uraian File Trans Masuk Detail

\begin{tabular}{|l|l|l|l|}
\hline Attribute & Data type & Length & Key \\
\hline Kd_jkm & Varchar & 8 & Kunci Tamu \\
\hline Debet & Double & & \\
\hline Kredit & Double & & \\
\hline Kode_akun & Varchar & 6 & Kunci Tamu \\
\hline
\end{tabular}

File trans_masuk_detail yang digambarkan pada tabel 6 merupakan tabel pembantu untuk menguraikan akun-akun apa saja yang digunakan pada transaksi kas masuk, sehingga file ini tidak memiliki kunci utama melainkan hanya memiliki kunci tamu saja. 
f. Uraian File Transaksi Kas Keluar

Tabel 7. Uraian File Transaksi Keluar

\begin{tabular}{|l|l|l|l|}
\hline Attribute & Data type & Length & Key \\
\hline Kd_jkk & Varchar & 8 & Kunci Utama \\
\hline No_bukti & Varchar & 10 & \\
\hline Tgl_jkk & Date & Short date & \\
\hline Keterangan & Varchar & 50 & \\
\hline Jumlah & Double & & \\
\hline Id_penerima & Char & 5 & Kunci Tamu \\
\hline
\end{tabular}

Sama halnya dengan file transaksi kas masuk, uraian file transaksi kas keluar yang digambarkan pada tabel 7 juga digunakan untuk menyimpan data transaksi kas, yakni transaksi pengeluaran kas dari lembaga untuk kegiatan penunjangnya seperti pembayaran listrik, pembelian alat tulis kantor, pembayaran gaji karyawan dan lain sebagainya.

g. Uraian File Detail Transaksi Kas Keluar

Tabel 8. Uraian File Trans Keluar Detail

\begin{tabular}{|l|l|l|l|}
\hline Attribute & Data type & Length & Key \\
\hline Kd_jkk & Varchar & 8 & Kunci Tamu \\
\hline Debet & Double & & \\
\hline Kredit & Double & & \\
\hline Kode_akun & Varchar & 6 & Kunci Tamu \\
\hline
\end{tabular}

Tabel 8 menggambarkan uraian dari file transaksi detail kas keluar yang digunakan untuk menyimpan data lebih detail mengenai akun-akun yang terlibat dalam pencatatan transaksi dana kas yang dikeluarkan lembaga.

4. Diagram Aktivitas (Activity Diagram)

Fungsi diagram aktivitas atau activity diagram adalah untuk menggambarkan bagaimana urutan dari proses aktifitas sebuah sistem dijalankan, sehingga pengguna sistem akan memahami bagaimana menggunakan sistem tersebut. Berikut ini akan digambarkan beberapa diagram aktivitas yang ada pada SIAPAK.

a. Diagram aktivitas Login

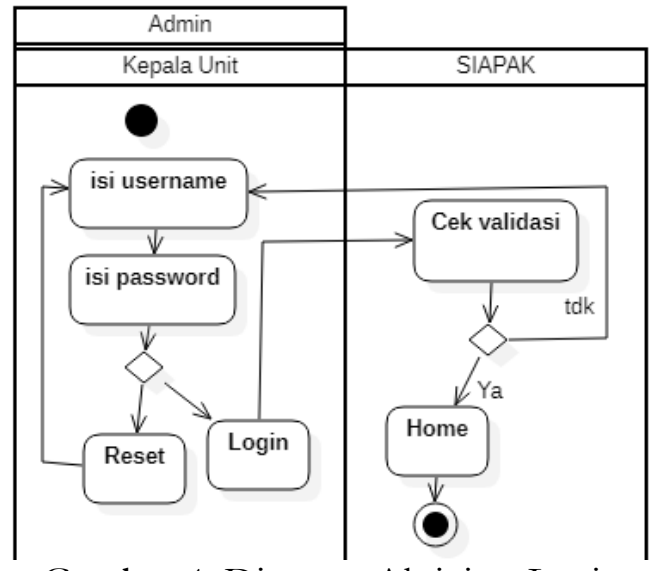

Gambar 4. Diagram Aktivitas Login 
Gambar 4 memberikan gambaran bagaimana proses alur akitvitas seorang pengguna agar dapat masuk ke sistem yang dibangun. Form login tentu digunakan agar menjaga bahwa sistem yang dibangun hanya dapat diakses oleh pengguna tertentu yang sudah diberikan hak akses. Ketika pengguna sistem mengisi data di form login maka SIAPAK akan memeriksa keabsahan dari data yang diisi. Jika berhasil maka SIAPAK akan menuju ke halaman utama (home page) dari sistem tersebut, namun jika tidak valid maka sistem akan menolak dan form login akan kembali kosong.

b. Diagram aktivitas menu master

Ada beberapa menu dalam SIAPAK yang berisi data master diantaranya data akun, data penerima dan data user. Ketiga menu tersebut memiliki alur aktivitas yang sama, berikut gambaran diagram aktivitas untuk data master tersebut.

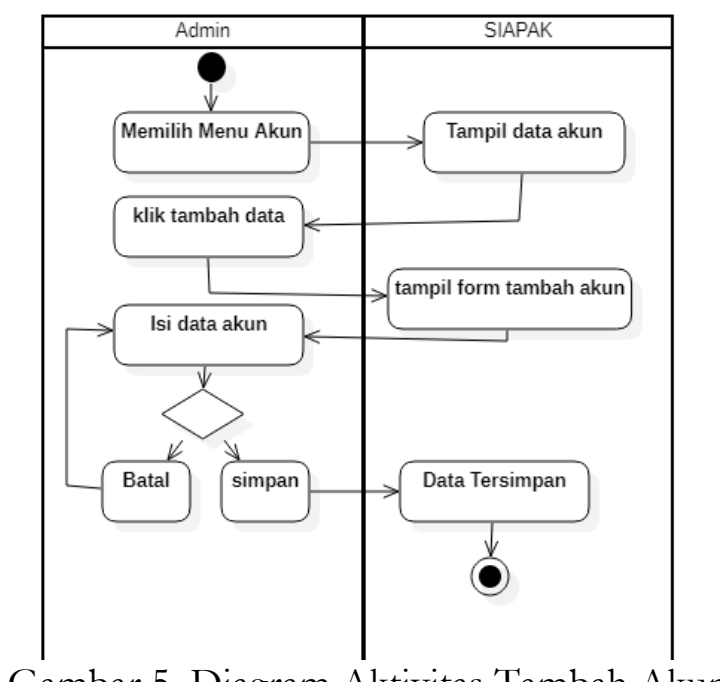

Gambar 5. Diagram Aktivitas Tambah Akun

Pada gambar 5 dijelaskan bahwa saat pengguna memilih salah satu menu master yang ada, maka sistem akan menampilkan data-data yang sudah tersimpan, kemudian jika pengguna akan menambah data baru, maka pengguna akan diarahkan ke form untuk mengisi data baru.

c. Diagram aktivitas menu transaksi

Menu transaksi dari pada aplikasi SIAPAK ini terdiri dari dua jenis yakni transaksi pencatatan dana kas masuk dan pencatatan dana kas keluar. Berikut diagram aktivitasnya 


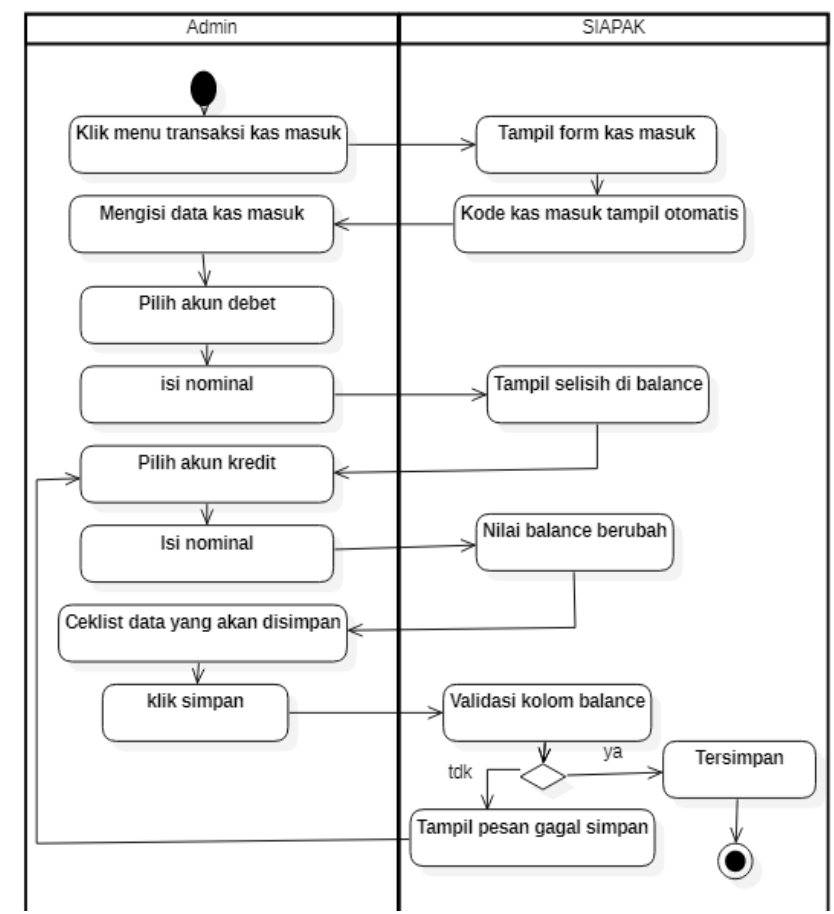

Gambar 6. Diagram Aktivitas Pencatatan Kas Masuk

Pada gambar 6 dijelaskan bahwa pengguna harus mengisikan data kas dengan teliti, dimana pengguna harus memahami akun-akun apa saja yang harus digunakan saat pencatatan transaksi terjadi sehingga nilai pada kolom debet dan kredit harus seimbang atau balance. Hal ini ditandai dengan kolom balance akan bernilai 0. Ketika pengguna akan menyimpan data yang diisi, pengguna diwajibkan menceklist data tersebut agar data tersimpan dengan benar.

5. Desain Antar Muka SIAPAK

a. Tampilan Login SIAPAK

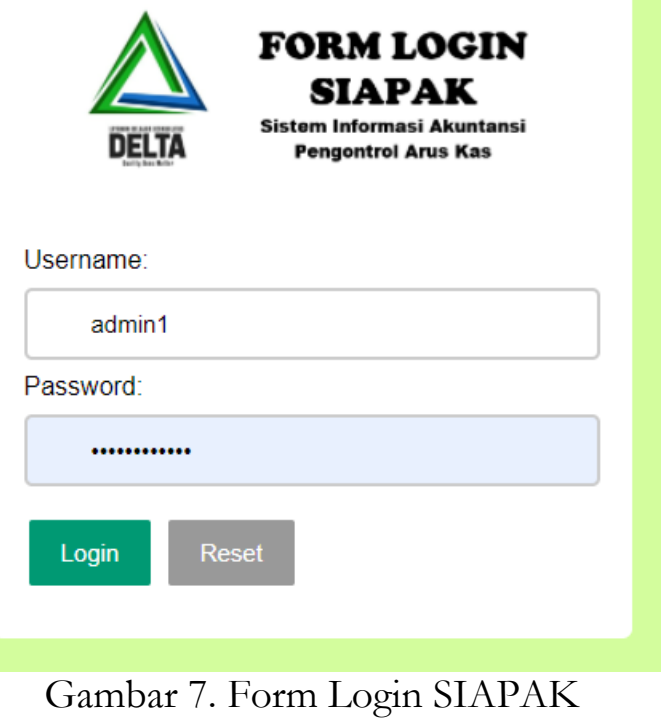


Ratnawati ${ }^{1}$, Patimah Ulwiyah ${ }^{2}$ Dea Julianti Siswoyo ${ }^{3}$

@ is The Best: Accounting Information Systems and Information Technology Business Enterprise

ISSN: 2252-9853 (Print) | ISSN: 2656-808X (Online)

Gambar 7 merupakan tampilan awal untuk pengguna sebelum masuk ke dalam sistem yang dirancang.

b. Tampilan Halaman Home SIAPAK

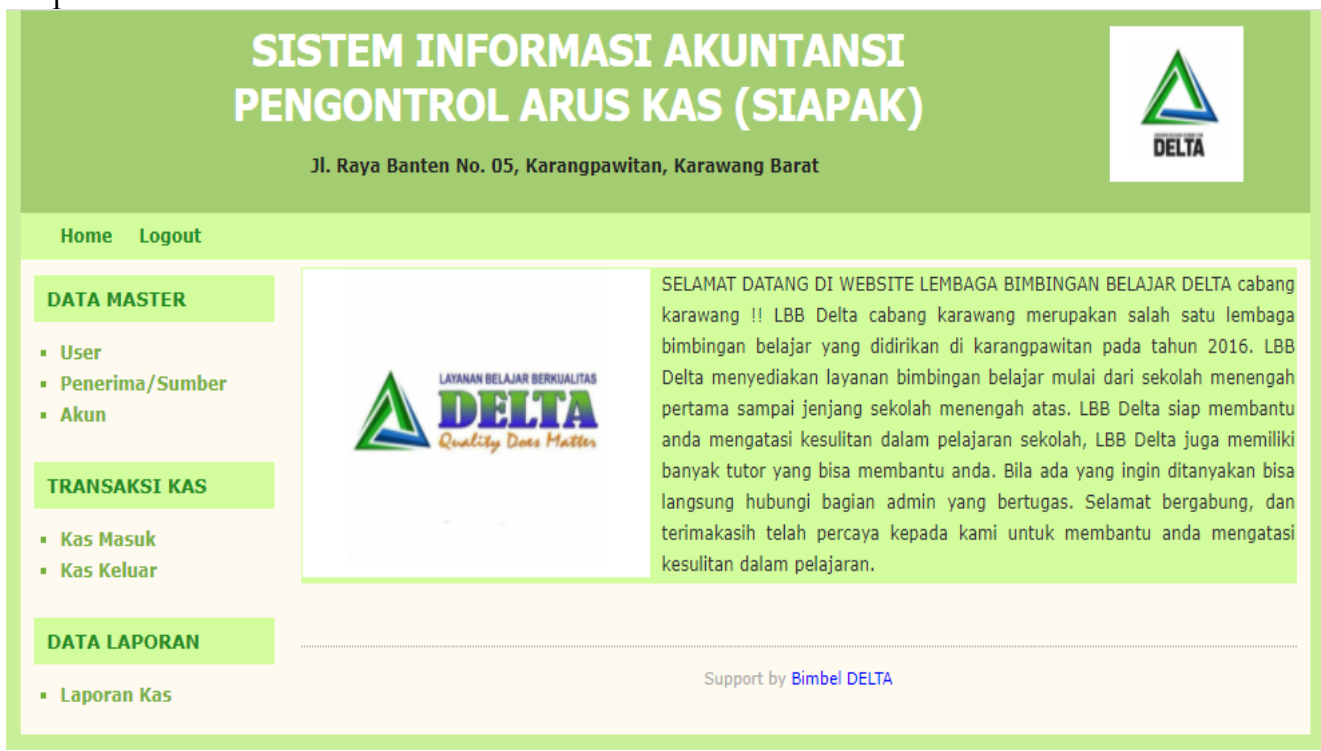

Gambar 8. Halaman Home SIAPAK

Halaman ini berupa halaman awal dari sistem yang dibuat dengan side bar yang menujukkan link menu yang dapat diakses oleh pengguna.

c. Tampilan Halaman Menu Master

\begin{tabular}{|c|c|c|c|}
\hline \multicolumn{4}{|c|}{ DATA AKUN } \\
\hline KODE AKUN & NAMA AKUN & KELOMPOK AKUN & AKSI \\
\hline $1-1101$ & Kas Kecil & Harta & EDIT II HAPUS \\
\hline $1-1102$ & Kas & Harta & EDIT II HAPUS \\
\hline $1-1103$ & Bank BCA & Harta & EDIT II HAPUS \\
\hline 1-2101 & Alat Tulis Kantor & Harta & EDIT II HAPUS \\
\hline $1-2201$ & Piutang Usaha & Harta & EDIT II HAPUS \\
\hline $1-2202$ & Piutang Karyawan & Harta & EDIT II HAPUS \\
\hline $4-1101$ & Pendapatan Uang Pendaftaran & Pendapatan & EDIT II HAPUS \\
\hline 4-1102 & Pendapatan Uang Bimbingan & Pendapatan & EDIT II HAPUS \\
\hline 5-1101 & Beban Gaji & Beban & EDIT II HAPUS \\
\hline 5-1102 & Beban listrik,air \& telpon & Beban & EDIT II HAPUS \\
\hline 5-1103 & Beban lain-lain & Beban & EDIT II HAPUS \\
\hline & Tamb: & & \\
\hline
\end{tabular}

Gambar 9. Halaman Data Akun

Volume 6 Nomor 2 (2021) Hal. 151-165 


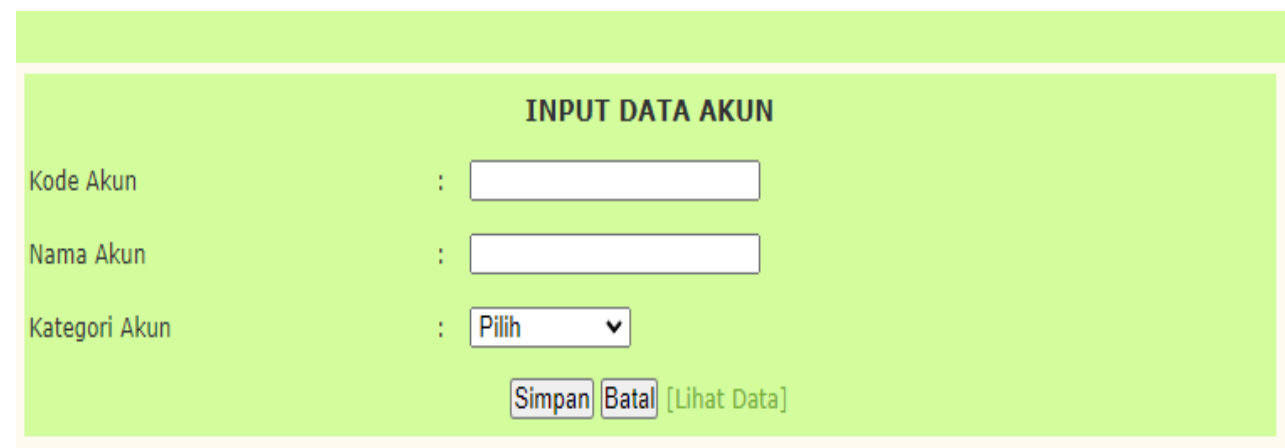

Gambar 10. Halaman Form Tambah Akun

Gambar 9 serta gambar 10 ialah tampilan dari salah satu menu halaman master yakni halaman akun. Seperti yang sudah dijelaskan pada diagram kativitas sebelumnya bahwa pengguna yang memilih salah satu menu master maka akan diperlihatkan data-data yang sudah disimpan sebelumya, kemudian jika akan mebambah data baru, maka terdapat link yang akan menuju form untuk mengisi data baru.

d. Tampilan Halaman Transaksi

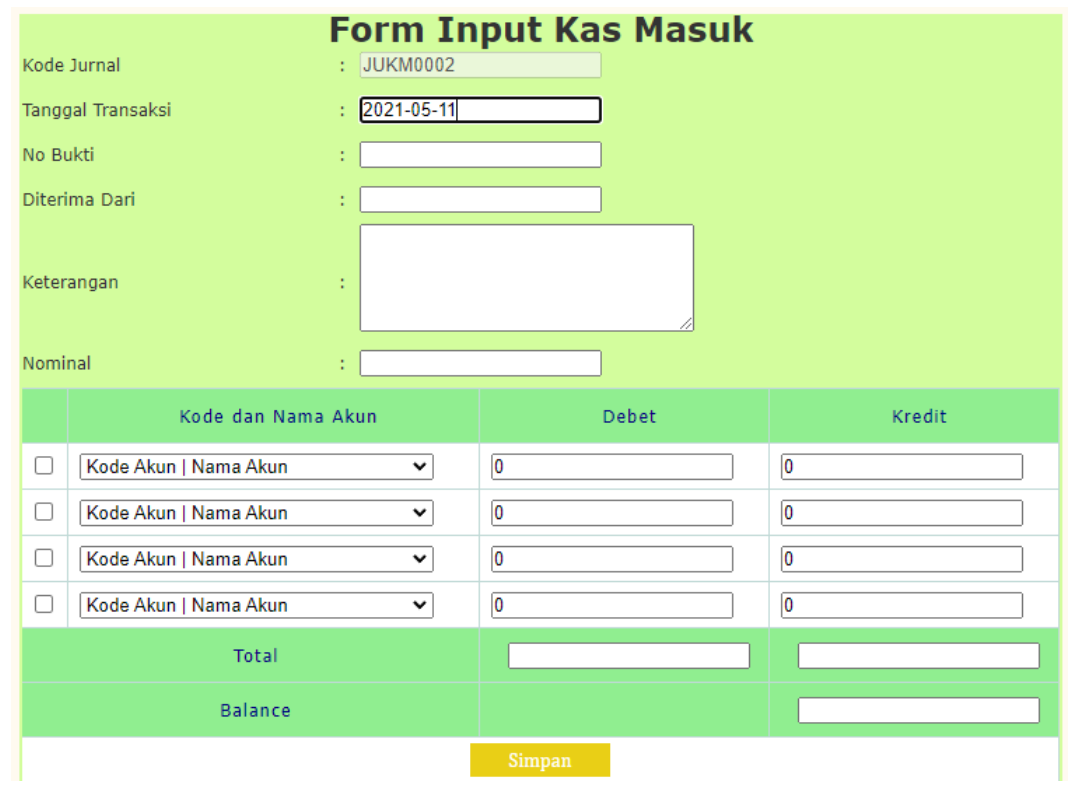

Gambar 11. Halaman Form Kas Masuk

Gambar 11 merupakan tampilan halaman transaksi yakni kas masuk. Pada halaman ini terdapat kode jurnal yang terisi otomatis dan tidak dapat diubah oleh pengguna. Hal ini ditujukan agar data yang diisikan tidak terjadi redudansi atau duplikat pencatatan. Sedangkan nomor bukti diisi berdasarkan bukti transaksi yang dimiliki. 
e. Tampilan Laporan Kas

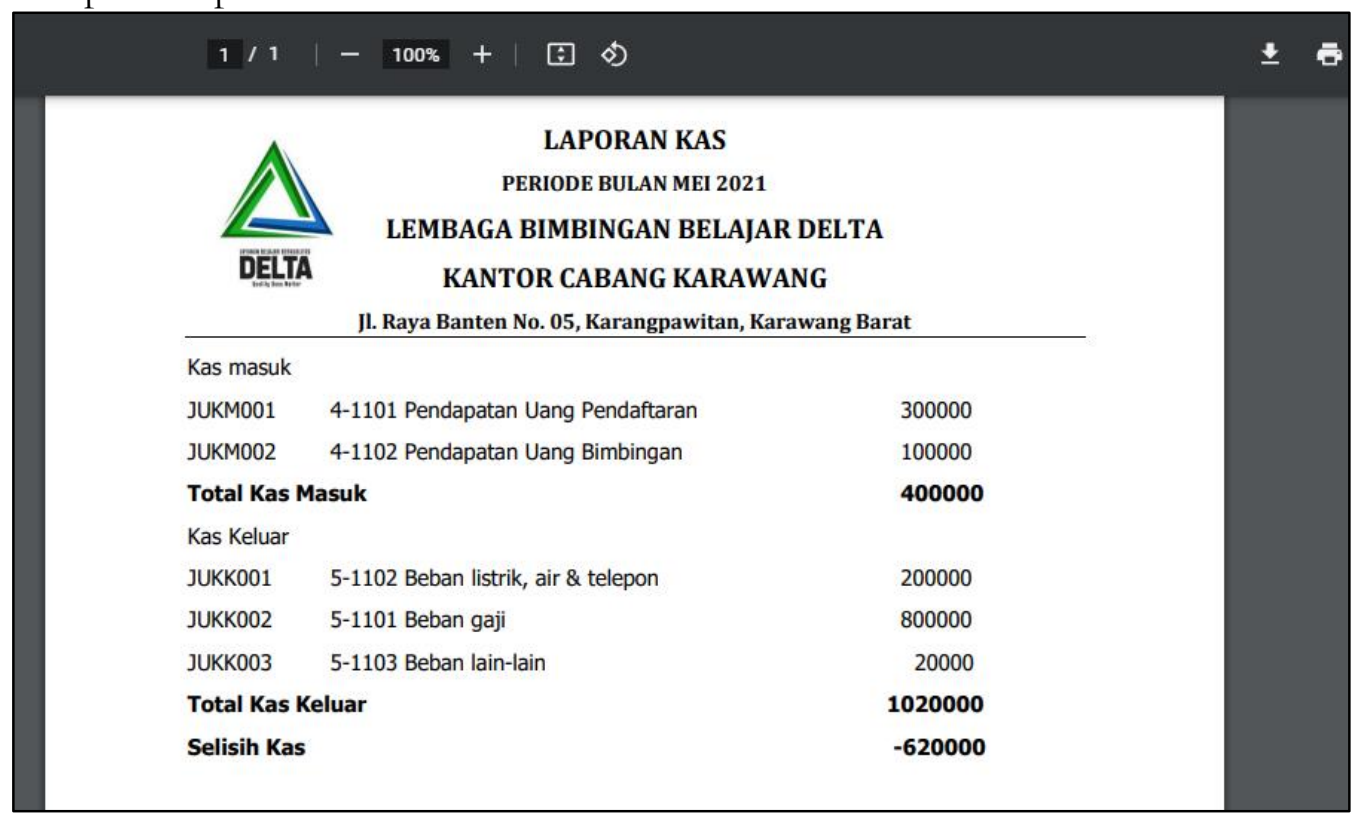

Gambar 12. Laporan Kas SIAPAK

Pada gamabr 12. Laporan kas pada SIAPAK disajikan dalam format pdf sehingga laporan akan mudah dicetak. Pada nominal selisih kas menunjukkan adanya selisih antara kas yang masuk dan kas yang dikeluarkan. Jika nilainya negatif artinya pengeluaran lebih besar daripada penadpatan.

C. Tahap Penerapan

Sebelum dilakukannya penerapan aplikasi SIAPAK ini, terlebih dahulu dilakukan pengujian terhadap sistem agar saat sistem digunakan, maka sistem sudah terbebas dari kesalahan (error). Pengujian dilakukan dengan metode uji blackbox. Berikut tabel hasil pengujian yang dilakukan.

Tabel 9. Penguijan Blackbox Pada SIAPAK

\begin{tabular}{|l|l|l|l|}
\hline \multicolumn{1}{|c|}{ Uraian Pengujian } & \multicolumn{1}{|c|}{ Contoh Pengujian } & \multicolumn{1}{|c|}{ Harapan } & Keluaran \\
\hline $\begin{array}{l}\text { Salah satu data login } \\
\text { diisi dengan data yang } \\
\text { salah }\end{array}$ & $\begin{array}{l}\text { Username: benar } \\
\text { Password: salah }\end{array}$ & $\begin{array}{l}\text { SIAPAK akan menolak } \\
\text { dan form login kosong } \\
\text { kembali }\end{array}$ & Benar \\
\hline $\begin{array}{l}\text { Semua kolom data } \\
\text { login diisi dengan } \\
\text { benar }\end{array}$ & $\begin{array}{l}\text { Username: benar } \\
\text { Password: benar }\end{array}$ & $\begin{array}{l}\text { SIAPAK mengarahkan ke } \\
\text { menu home }\end{array}$ & Benar \\
\hline $\begin{array}{l}\text { Form menu master } \\
\text { tidak diisi lengkap } \\
\text { kemudian disimpan }\end{array}$ & Nama akun tidak diisi & $\begin{array}{l}\text { Penyimpanan gagal dan } \\
\text { SIAPAK menampilkan } \\
\text { warning data belum lengkap }\end{array}$ & Benar \\
\hline $\begin{array}{l}\text { Form menu master } \\
\text { diisi dengan kode yang } \\
\text { sama, kemudian } \\
\text { disimpan }\end{array}$ & $\begin{array}{l}\text { Kode akun diisi } \\
\text { dengan data yang } \\
\text { sama }\end{array}$ & $\begin{array}{l}\text { Penyimpanan gagal dan } \\
\text { SIAPAK menampilkan } \\
\text { pesan warning duplikasi } \\
\text { data }\end{array}$ & Benar \\
\hline
\end{tabular}




\begin{tabular}{|c|l|l|l|}
\hline Uraian Pengujian & \multicolumn{1}{|c|}{ Contoh Pengujian } & \multicolumn{1}{|c|}{ Harapan } & Keluaran \\
\hline $\begin{array}{l}\text { Form transaksi diisi } \\
\text { dengan data yang tidak } \\
\text { seimbang (balance) }\end{array}$ & $\begin{array}{l}\text { Nominal debet: diisi } \\
\text { Nominal kredit: } \\
\text { kosong }\end{array}$ & $\begin{array}{l}\text { Kolom balance tidak } \\
\text { bernilai 0 atau tidak } \\
\text { seimbang }\end{array}$ & Benar \\
\hline $\begin{array}{l}\text { Form transaksi diisi } \\
\text { dengan data yang } \\
\text { seimbang (balance) }\end{array}$ & $\begin{array}{l}\text { Nominal debet: } \\
100000 \\
\text { Nomimal kredit: } \\
100000\end{array}$ & $\begin{array}{l}\text { Kolom balance bernilai 0 } \\
\text { atau seimbang }\end{array}$ & Benar \\
\hline $\begin{array}{l}\text { Form transaksi tidak di } \\
\text { cecklist kemudian } \\
\text { disimpan }\end{array}$ & $\begin{array}{l}\text { Akun debet tidak di } \\
\text { ceklist }\end{array}$ & $\begin{array}{l}\text { Penyimpanan gagal dan } \\
\text { SIAPAK menampilkan } \\
\text { pesan warning gagal simpan }\end{array}$ & Benar \\
\hline
\end{tabular}

Langkah terakhir setelah pengujian tentu adalah uji coba terhadap aplikasi yang dibangun kepada pengguna. Beberapa hambatan yang terjadi selama pengembangan aplikasi ini antara lain adalah bagaimana merealisasikan fungsionalitas kebutuhan pengguna menjadi sebuah antar muka pemakai aplikasi yang mudah untuk digunakan. Selain itu penerapan aplikasi ini merupakan hal baru bagi karyawan sehingga membutuhkan pelatihan untuk penyesuaian dengan penggunaanya di masa mendatang.

\section{Kesimpulan}

Sistem Informasi Akuntansi Pengontrol Arus Kas (SIAPAK) yang dibangun menggunakan metode pengembangan Rapid Application Development dapat membantu permasalahan pencatatan kas pada lembaga bimbingan belajar Delta khususnya di kantor cabang Karawang. Dengan penggunaan SIAPAK admin diharapkan agar dapat mengisi data secara aktual sesuai terjadinya transaksi sehingga tidak lagi ada data yang tertinggal untuk dicatat. Selain itu kepala unit dapat mencetak laporan dengan mudah tanpa harus merekap kembali pencatatan transaksi kas yang masuk maupun yang keluar. Penelitian ini penting untuk dilakukan terutama pada perusahaan yang diteliti yakni sebagai solusi dari permasalahan yang terjadi agar dapat memberikan dampak positif bagi perusahaan tersebut.

\section{Ucapan Terima Kasih}

Penulis sampaikan terima kasih terutama kepada responden yang telah ikut berpartisipasi pada penelitian kami, bapak Ahmad Didi selaku Kepala Unit Delta Cabang Karawang. Asisten penelitian Lintang Kinasih, Muzalifah dan Fitri Hikmawanti yang juga membantu dalam proses pengambilan data serta seluruh pihak yang terlibat hingga penelitian ini dapat berjalan dengan lancar.

\section{Daftar Pustaka}

[1] Supriyati, R. S. Bahri, and E. Komarudin, "Computerized of International Financial Report Standard for Good Governance in Small Medium Enterpreses," in IOP Conference Series: Materials Science and Engineering, 2019, vol. 662, no. 5, doi: 10.1088/1757899X/662/5/052009.

[2] A. Anna, N. Nurmalasari, and A. E. Yusnita, "Rancang Bangun Sistem Informasi Akuntansi Penerimaan dan Pengeluaran Kas pada Kantor Camat Pontianak Timur," J. Khatulistiwa Inform., vol. 6, no. 2, pp. 107-118, 2018, doi: 10.31294/khatulistiwa.v6i2.153.

[3] R. I. N. Paulus Mariano Alfonso Molo, Barsilius Lucky Widiarsa, Ahmad Al Kaafi, "Rancang Bangun Sistem Informasi Akuntansi Arus Kas Pada PT. Adhiyastha Dhiwa Insani," J. Teknol. Infnormatika dan Komput., vol. 5, no. 2, pp. 24-32, 2019. 
[4] M. Abdurahman, A. Thalib, and A. Ambarita, "Sistem Informasi Akuntasi Arus Kas Pada Kantor Desa Bobaneigo Kec.Kao Teluk Kabupaten Halmahera Utara," IJIS - Indones. J. Inf. Syst., vol. 4, no. 2, pp. 78-86, 2019, doi: 10.36549/ijis.v4i2.56.

[5] S. B. Hartono and A. F. Shauqy, "Pengembangan Sistem Informasi Arus Kas Dengan Metode Sdlc (System Development Life Cycle) Pada Madin Al-Junnah," ISOQUANT J. Ekon. Manaj. dan Akunt., vol. 4, no. 1, pp. 1-16, 2020, doi: 10.24269/iso.v4i1.337.

[6] N. Nurmalasari, A. Anna, and F. Ilmi, "Sistem Informasi Kas Masuk Dan Kas Keluar Berbasis Web Pada Pt Rakha Rekananta Pontianak," Swabumi, vol. 8, no. 1, pp. 59-70, 2020, doi: 10.31294/swabumi.v8i1.7433.

[7] M. Kabuhung, "Sistem Informasi Akuntansi Penerimaan Dan Pengeluaran Kas Untuk Perencanaan Dan Pengendalian Keuangan Pada Organisasi Nirlaba Keagamaan," J. EMBA J. Ris. Ekon. Manajemen, Bisnis dan Akunt., vol. 1, no. 3, pp. 339-348, 2013, doi: 10.1017/CBO9781107415324.004.

[8] S. Mulyani, E. Kasim, W. Yadiati, and H. Umar, "Influence of accounting information systems and internal audit on fraudulent financial reporting," Opcion, vol. 35, no. 21, pp. 323-338, 2019.

[9] A. C. Nugroho, "Sistem Presensi Online Berdasarkan Metode Rapid Application Development Menggunakan Block Programming," J. Appl. Comput. Sci. Technol., vol. 2, no. 1, pp. 1-6, 2021, doi: 10.52158/jacost.v2i1.107.

[10] Subianto, "Penerapan Metode Rapid Application Development dalam Perancangan Sistem Informasi Pendataan," J. Infokam, vol. XVI, no. 1, pp. 46-54, 2020.

[11] Arliyana and H. Riyadli, "Penerapan Rapid Application Development pada Pengembangan Sistem Informasi Penanganan Lahan Gambut Palangka Raya," J. Ilm. Tek. Inform. dan Sist. Inf., vol. 9, no. 2, pp. 31-40, 2020.

[12] R. Sulistiowati, R. R. R. Widjajanti, and E. Susanti, "Pengaruh Laba Akuntansi dan Arus Kas Terhadap Harga Saham Pada Perusahaan Dagang Yang Terdaftar Di Bursa Efek Indonesia (BEI)," J. Econ. Sustain. Dev., vol. 3, no. 1, pp. 20-29, 2018, doi: 10.33086/amj.v3i2.1316.

[13] G. F. Fitriana, "Pengujian Aplikasi Pengenalan Tulisan Tangan Menggunakan Model Behaviour Use Case," J. Tek. Inform. dan Sist. Inf., vol. 7, no. 2, p. 200, 2020.

[14] S. P. Effendi and E. Tasrif, "Perancangan Digitalisasi Pelayanan Administrasi Akademik Jurusan Teknik Elektronika Berbasis Android,” VOTEKNIKA J. Vokasional Tek. Elektron. dan Inform., vol. 7, no. 2, pp. 132-137, 2019. 